\title{
Investigating Procrastination in Higher Education
}

\author{
Abdul Saman \\ Universitas Negeri Makassar \\ Makassar, Indonesia \\ abdulsaman72@gmail.com
}

\begin{abstract}
This study aims at investigating procrastination among students in higher education. Procrastination has been studied in many fields including Psychology, Mental Health, and Educational studies. This study brings the important idea to the study of procrastination. Unlike other perspectives, this study only focused on academic procrastination where the students delay their efforts to complete any academic tasks. Participants were 230 college students majoring in Educational Psychology and Guidance. The students $(\mathrm{N}=349$ students) were recruited randomly for the survey. The data, then, were analyzed using quantitative approach. The results showed that most participants $\mathbf{( 4 3 . 0 4 \% )}$ ) were less involved in procrastination while few of them $(\mathbf{1 0 . 8 7 \%})$ showed low frequency of procrastination. This research suggested that the moderate level of procrastination indicated a high degree of procrastination.
\end{abstract}

Keywords—procrastination; higher education

\section{INTRODUCTION}

Education is one effort to educate the community of the nation. The success of a nation to advance its educational activities is an indicator of success in human resource development. Higher education as one level of education requires completion of the study for learners promptly. Universitas Negeri Makassar as one of the education providers in Indonesia experienced constraints when completing the study. There are more than $60 \%$ of students completing the study over eight semesters. This study aims to examine the reasons for delaying completion of student research.

Students who are late in completing the study have psychological difficulties or commonly referred to as procrastination. Various definitions of procrastination are outlined by experts. Inability to manage and utilize time is a sign of academic procrastination [1]. Procrastination is a tendency to delay any effort in starting or completing academic tasks while engaging in less important activities [2].

Also, Harriott and Ferrari proposed four indicators to identify procrastination: Delay in starting and completing tasks, being slow in doing work or task, gaps between planning and actual work and overlay enjoy leisure time while ignoring main task [3].

College students do not always possess this time management skill. Goleman argued that many students not have adequate skills in managing their time. As a result, they engaged in ineffective time management [4].
Muchinsky conducted a study among college students in 2007. The study found that out of 1,502 graduates in East Java, there were 938 completed their final paper a month before the commencement day while $83 \%$ were late in completing their degrees [5]. Unsurprisingly, the procrastination was the main reason behind all these delays.

Rahardjo et al. found that students in both private and public universities had a similar level of procrastination [6]. Alternatively, the university types contribute insignificant effect to the student's procrastination. Many students in higher education institute are fully engaged while doing extra works or something unrelated to their academic tasks [7].

Some studies found that procrastination was serious issues in many universities. For instance, $70 \%$ students procrastinated their final paper [8], 60\% considered procrastination as part of their academic lives [9], and nearly half students in one study procrastinated their academic tasks [10].

Some experts argue that procrastination is a sign of mental disorder and it is potentially treated by utilizing behavior modification technique, cognitive therapy, and other treatments [5].

Rahardjo, Juneman, and Setiani understand that students in higher education exert their energy to complete their degrees [6]. However, if the students are unable to control their excessive procrastination, it possibly leads to severe mental health problems [11]. Moreover, procrastination can be affected by both internal (individual) and external (others and environment) factors [12].

Also, students may procrastinate their work while they still benefit from doing it, this is what experts call functional procrastination. In contrast, excessive procrastination and avoiding work towards the goals; this is so-called dysfunctional procrastination [3].

This study focuses on investigating the dysfunctional procrastination among college students in the university. The finding contributes important knowledge to the understanding of procrastination in higher-level education.

\section{RESEARCH METHOD}

\section{A. Participant}

Participants were students $(n=230)$ majoring in Educational Psychology and Guidance. They were randomly 
recruited from 340 students enrolling in the program within the year of 2010 to 2015. Most of the participants were female $(65 \%)$. The students participated in the study for a 10-point course credit.

\section{B. Measure and Procedure}

The authors constructed a new measure of procrastination as no records were found for the psychometric property of the Procrastination scale in Indonesia. The new scale was based on Ferrari's indicators of procrastination [12]. The items were administered using a Likert-type scale ranging from 1 (strongly disagree) to 5 (strongly agree). The participants completed the survey using traditional paper-and-pencil test.

\section{RESULTS AND DISCUSSION}

There were four dimensions which can explain procrastination among students (i.e., Delay, Slow work, the gap between planning and completion, and overuse of leisure time). The results yielded that only few students committed to very high procrastination across the four dimensions $(\mathrm{n}<1 \%)$. In contrast, there were more students in either moderate or low procrastination.

The result of research of four dimensions are described in figure 1, figure 2, figure 3 and figure 4 .

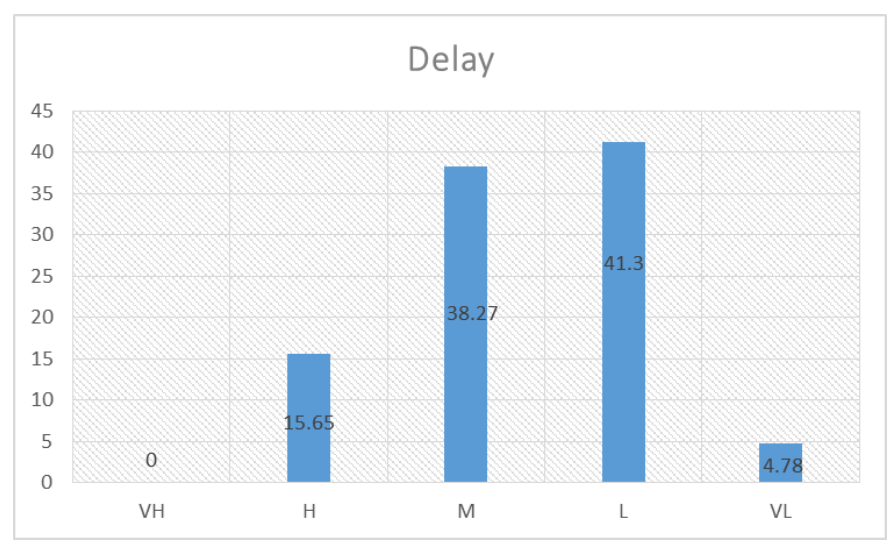

Fig. 1. Procrastination in delay aspects

Figure 1 illustrates that $41.3 \%$ of students often delay completing their tasks of studies. Only a small portion of $4.78 \%$ of students who very often delayed completing their college assignments. Delaying habits for students is caused by a sense of fear of failure. Feelings of fear are a feeling of disbelief and waiting for the direction and guidance of the lecturer. Also, some students work slowly in completing academic tasks. The reason for slow work is due to difficult college assignments or many other academic duties. The description of the students' slow working habits is presented in Figure 2.

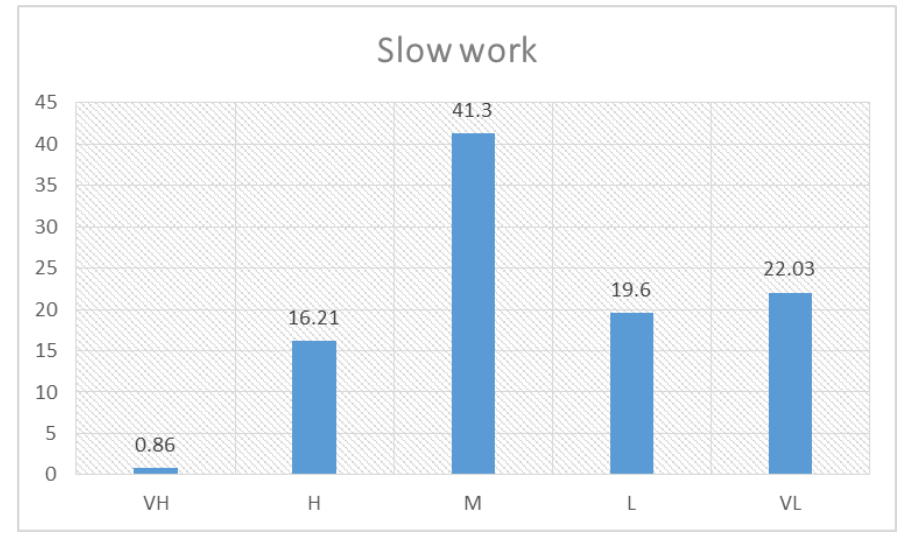

Fig. 2. Procrastination in slow work aspects

Fig 2 explains slow work habits indicating average level $(41.3 \%)$, high level $(16.21 \%)$ and very high level $(0.86 \%)$. Procrastination in the slow-working habits of college students indicates that there is a low of $22.03 \%$ in the low category. Fig. 3 describes the difference between actual planning and conditions. The reason for the procrastination due to the gap is that there are things that are not taken into account at the time of planning such as interference friends, difficulty getting references and relax habits. Figure 3 illustrates that the gap between planning and actual conditions has a low effect on procrastination. A total of $43.04 \%$ of respondents stated the gap is in a low category. There are only $10.45 \%$ who write gaps as procrastination reasons.

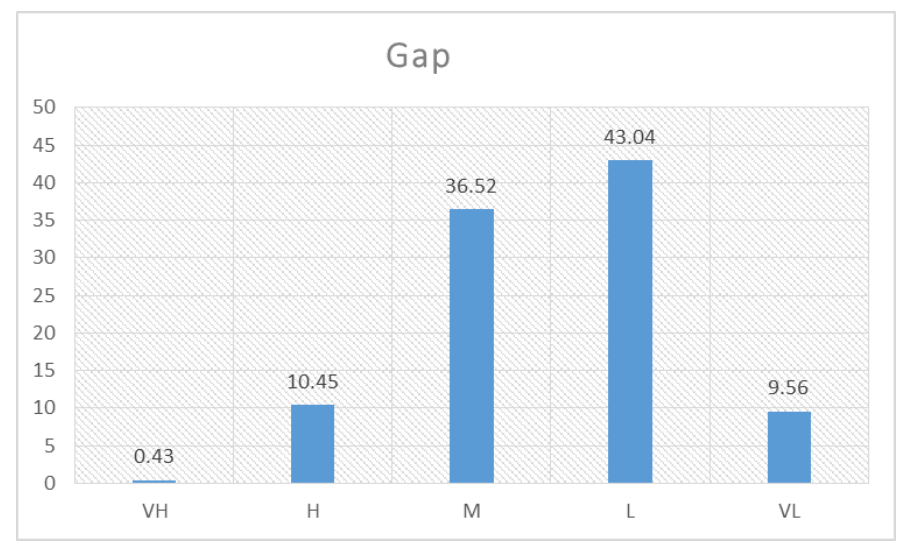

Fig. 3. Procrastination in gap aspects

Relaxing habits or not using the leisure time is also not used as a reason for procrastination by students. Figure 4 shows that leisure time is generally low $(53.47 \%)$ and there are only $4.37 \%$ who rated the reason for leisure as the cause of procrastination.

The results show that slow work habits are the main reason respondents are associated with procrastination on academic. 


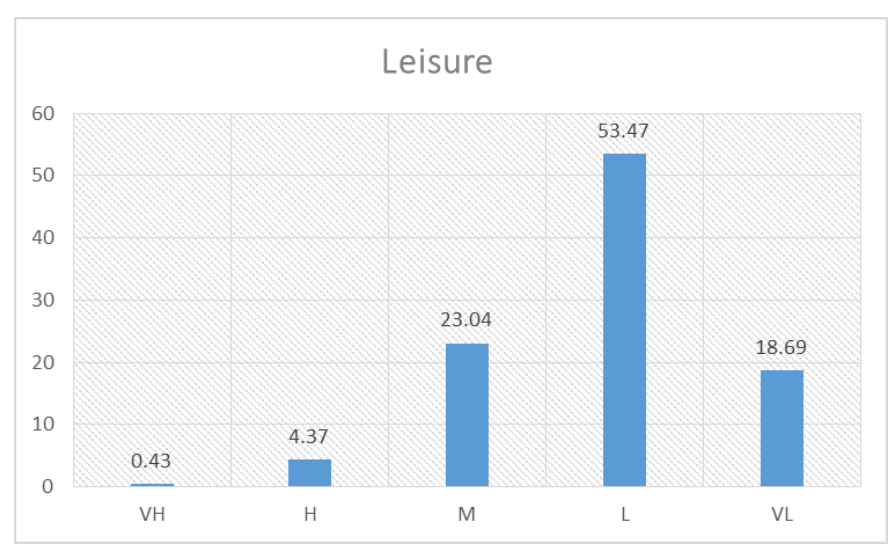

Fig. 4. Procrastination in leisure aspects

Although the percentages did not match exactly the previous studies [8]-[10], the results were still consistent with the previous ones. The students had various degree of procrastination. The students tended to postpone their efforts to complete their academic works.

Future studies should investigate other factors that potentially influence procrastination. Likewise, the effect of procrastination on academic performance should be explored.

\section{CONCLUSIONS}

This study was an initial endeavor to understanding academic procrastination. The findings were in-line with several studies. Most participants were high in the slow-work dimension while they were still moderate or low in other aspects.

\section{References}

[1] P. Rosário, M. Costa, J. C. Núñez, J. González-Pienda, P. Solano, and A. Valle, "Academic procrastination: Associations with personal, school, and family variables," Span. J. Psychol., vol. 12, no. 1, pp. 118-127, 2009.

[2] F. S. Azar, "Self-efficacy, Achievement Motivation, and Academic Procrastination as Predictors of Academic Performance," US-China Educ. Rev., vol. 3, no. 11, pp. 847-857, 2013.

[3] J. Harriott and J. R. Ferrari, "Prevalence of procrastination among samples of adults," Psychol. Rep., vol. 78, no. 2, pp. 611-616, 1996.

[4] D. Goleman, "The Secret to Success.," Educ. Dig. Essent. Readings Condens. Quick Rev., vol. 74, no. 4, pp. 8-9, 2008.

[5] P. M. Muchinsky, Psychology applied to work: An introduction to industrial and organizational psychology. Cengage Learning, 2006.

[6] W. Rahardjo, J. Juneman, and Y. Setiani, "Computer anxiety, academic stress, and academic procrastination on college students," J. Educ. Learn., vol. 7, no. 3, pp. 147-152, 2013.

[7] E. Lee, "The relationship of motivation and flow experience to academic procrastination in university students," J. Genet. Psychol., vol. 166, no. 1, pp. 5-15, 2005.

[8] A. Ellis and W. J. Knaus, Overcoming procrastination: or, how to think and act rationally in spite of life's inevitable hassles. Signet, 1979.

[9] F. J. Bruno, Psychological symptoms. John Wiley \& Sons, 1993.

[10] P. Steel, "The nature of procrastination: a meta-analytic and theoretical review of quintessential self-regulatory failure." American Psychological Association, 2007.

[11] D. Glenn, "Procrastination in college students is a marker for unhealthy behaviors, study indicates," Chron. High. Educ., vol. 26, 2002.

[12] R. E. Slavin and N. Davis, "Educational psychology: Theory and practice," 2006. 